Check for updates

1 University of Manchester, Manchester, UK

2 University of Nottingham, Nottingham, UK

3 De Montfort University, Leicester, UK

4 London School of Hygiene and Tropical Medicine, London, UK

Correspondence to: R M Agius rmagius@doctors.org.uk

Cite this as: BMJ2020;370:m3577 http://dx.doi.org/10.1136/bmj.m3577 Published: 21 September 2020

\section{Covid-19 in the workplace}

\section{Reporting guidance should reflect risks to a wide range of workers}

\author{
Raymond M Agius, ${ }^{1}$ John F R Robertson, ${ }^{2}$ Denise Kendrick, ${ }^{2}$ Herb F Sewell, ${ }^{2}$ Marcia Stewart, ${ }^{3}$ \\ Martin McKee
}

Faced with a novel lethal virus, employers have struggled to implement their legal duty to protect staff from harm in the workplace. There is no international case definition for attributing an occupational origin to covid-19 cases, and the World Health Organization has so far prepared a surveillance protocol only for healthcare workers. ${ }^{1}$ Employers are accountable, in the UK, to the Health and Safety Executive (HSE) and must notify it when there is "reasonable evidence" of a worker contracting covid-19 through occupational exposure. ${ }^{23}$ In general, HSE expects to be notified if it is "more likely than not that the person's work was the source of exposure-as opposed to general societal exposure." However, HSE also states that work with the general public-as opposed to work with people known to be infected-is not usually sufficient to trigger reporting. $^{2}$

HSE has published a technical summary of the 8666 notifications of covid-19 in workers in England, Scotland, and Wales, including 125 deaths, from 10 April to 8 August. ${ }^{4}$ Data before 10 April 2020 are excluded because of a change in methods. The weekly number of notifications peaked at 1183 (including 23 deaths) in the week ending 2 May 2020, two weeks later than the peak of deaths among the general population, as reported by the Office for National Statistics (ONS). ${ }^{5}$

\section{Missed cases}

At least 3354 (39\%) of the notified covid-19 cases were in people working in residential care and other social work, including $52(42 \%)$ deaths. A further 3382 cases (39\%) were among healthcare workers, including 50 (40\%) deaths. As HSE acknowledges, these figures misjudge the true scale of the problem because of widespread under-reporting by employers. Misclassification further limits the comparison between sectors. ${ }^{4}$

The ONS statistical bulletins ${ }^{6}$ have shown that age standardised mortality rates for male security guards and related occupations were nearly four times higher than those for all men of working age, while for taxi, cab, bus, and coach drivers the age standardised mortalities were well over double. Although ONS analyses exclude many deaths subject to coroners' inquests and do not yet take into account comorbidity, socioeconomic characteristics, or other factors such as ethnicity, they provide some comparative evidence on covid-19 deaths potentially associated with work. They are consistent with the conclusion that jobs with frequent and close public exposure (besides health and social care) carry a higher risk of covid-19. ${ }^{78}$ Such jobs should fall within the scope of future HSE reporting guidance and thus be subject to investigation.

Currently, HSE also intimates that if Public Health England (PHE) guidance on "effective control measures" ${ }^{9}$ has been followed at work, cases of covid-19 among employees do not always need to be reported to HSE. Some have argued ${ }^{10} 11$ that PHE's guidance does not offer adequate protection as it is consistent with the view that aerosol transmission is unlikely. ${ }^{12}$ However, emerging evidence suggests the need to take precautions against aerosol transmission. ${ }^{13} 14$

\section{Acting on evidence}

HSE should now encourage notification of covid-19 in health and social care workers who became infected despite having followed PHE's guidance. Investigation of these cases would enable lessons to be learnt, such as whether the more precautionary European guidance on respiratory protective equipment should be used (wearing respirators rather than surgical masks) while managing people with suspected covid-19. ${ }^{15}$

As detailed in the HSE guidance, ${ }^{2}$ doctors have an important role in notifying employers in writing (ordinarily with the patient's consent) of a diagnosis of covid-19. These reports should highlight the contribution of work related factors -for example, insufficient control measures. Moreover, some general practitioners who are employers have a legal duty as "responsible persons" to report to HSE, covid-19 attributed to occupational exposure in their employees. ${ }^{216}$ HSE has produced useful advice to help keep work safe during the covid-19 pandemic. ${ }^{17}$ Safety also relies on learning from experience, and HSE must act quickly to synthesise and disseminate what has been learnt to help prevent further death and disease among workers.

HSE should change its reporting guidance to reflect the risks in occupational sectors outside health and social care, and to consider whether current protective equipment and other control measures are adequate. The thousands of cases of covid-19 contracted at work warrant an urgent rapid review ${ }^{1819}$ of the national pandemic policy, followed by a full and wide ranging public inquiry. ${ }^{320}$

Competing interests: We have read and understood BMJ policy on declaration of interests and declare that MMcK is a member of the independent SAGE.

World Health Organization. Surveillance protocol for SARS-CoV-2 infection among health workers. 2020. https://apps.who.int/iris/rest/bitstreams/1278820/retrieve

Health and Safety Executive (UK). Further guidance on RIDDOR reporting of covid-19. 2020. https://www.hse.gov.uk/coronavirus/riddor/riddor-reporting-further-guidance.htm 
3 Agius R. Covid-19 and health at work. Occup Med (Lond) 2020;70:349-51. doi: 10.1093/occmed/kqaa075 pmid: 32347933

4 Health and Safety Executive. Technical summary of data on coronavirus (COVID-19) disease reports made by employers to HSE and local authorities since 10 April 2020 https://www.hse.gov.uk/statistics/coronavirus/index.htm

5 Office for National Statistics. Comparison of weekly death occurrences in England and Wales: up to week ending 10 July 2020. https://www.ons.gov.uk/peoplepopulationandcommunity/healthandsocialcare/causesofdeath/articles/comparisonofweeklydeathoccurrencesinenglandandwales/uptoweekending10july2020

6 Office for National Statistics. Coronavirus (COVID-19) related deaths by occupation, England and Wales: deaths registered between 9 March and 25 May 2020. 26 Jun 2020.

https://www.ons.gov.uk/peoplepopulationandcommunity/healthandsocialcare/causesofdeath/bulletins/coronaviruscovid19relateddeathsbyoccupationenglandandwales/deathsregisteredbetween9marchand25may2020

7 Sim MR. The COVID-19 pandemic: major risks to healthcare and other workers on the front line. Occup Environ Med 2020;77:281-2. doi: 10.1136/oemed-2020-106567 pmid: 32238444

8 Burdorf A, Porru F, Rugulies R. The COVID-19 (Coronavirus) pandemic: consequences for occupational health. Scand J Work Environ Health 2020:46:229-30 doi: 10.5271/sjweh.3893 pmid: 32356896

9 Public Health England. Guidance. COVID-19 personal protective equipment (PPE). Updated 18 June 2020. https://www.gov.uk/government/publications/wuhan-novel-coronavirus-infectionprevention-and-control/covid-19-personal-protective-equipment-ppe\#summary-of-ppe-recommendations-for-health-and-social-care-workers

10 Robertson JFR, Stewart M, Kendrick D, Sewell HF. Covid-19: Protect health and social care workers and refer their deaths to the coroner. BMJ Opinion, 21 Apr 2020.

https://blogs.bmj.com/bmi/2020/04/21/covid-19-protect-health-and-social-care-workers-andrefer-their-deaths-to-the-coroner/

11 Newman M. Covid-19: doctors' leaders warn that staff could quit and may die over lack of protective equipment. BMJ 2020;368:m1257. doi: 10.1136/bmj.m1257 pmid: 32217522

12 Klompas M, Baker MA, Rhee C. Airborne transmission of SARS-CoV-2 theoretical considerations and available evidence. JAMA 2020;324:441-2. doi: 10.1001/jama.2020.12458.

13 Fennelly KP. Particle sizes of infectious aerosols: implications for infection control. Lancet Respir Med 2020;8:914-24.pmid: 32717211

14 Morawska L, Milton DK. It is time to address airborne transmission of covid-19. Clin Infect Dis 2020;ciaa939. doi: 10.1093/cid/ciaa939 pmid: 32628269

15 European Centre for Disease Prevention and Control. Guidance for wearing and removing personal protective equipment in healthcare settings for the care of patients with suspected or confirmed COVID-19. 2020. https://www.ecdc.europa.eu/sites/default/files/documents/COVID-19-guidancewearing-and-removing-personal-protective-equipment-healthcare-settings-updated.pdf

16 Agius RM, Robertson JFR, Stewart M, Kendrick D, Sewell HF, McKee M. Covid-19: Rigorous investigation of healthcare workers' deaths is indispensable. BMJ Opinion, 12 May 2020 https://blogs.bmj.com/bmi/2020/05/12/covid-19-rigorous-investigation-of-healthcare-workersdeaths-is-indispensable/

17 Health and Safety Executive. Working safely during the coronavirus (COVID-19) outbreak. https://www.hse.gov.uk/coronavirus/working-safely/index.htm

18 McKee M, Gill M, Wollaston S. Public inquiry into UK's response to covid-19. BMJ 2020;369:m2052. doi: 10.1136/bmj.m2052 pmid: 32444349

19 Adebowale V, Alderson D, Burn W, etal. Covid-19: Call for a rapid forward looking review of the UK's preparedness for a second wave-an open letter to the leaders of all UK political parties. BMJ 2020;369:m2514. doi: 10.1136/bmj.m2514 pmid: 32576551

20 Dyer C. Covid-19: Doctors make bid for public inquiry into lack of PPE for frontline workers. BMJ 2020;369:m1905.pmid: 32398219

This article is made freely available for use in accordance with BMJ's website terms and conditions for the duration of the covid-19 pandemic or until otherwise determined by BMJ. You may use, download and print the article for any lawful, non-commercial purpose (including text and data mining) provided that all copyright notices and trade marks are retained. 